\title{
Primary culture of the region of the amebocyte-producing organ of the snail Biomphalaria glabrata, the intermediate host of Schistosoma mansoni
}

\author{
L Barbosa, LM Silva*, PMZ Coelho*****, SR Santos****, CL Fortes-Dias*/+
}

\begin{abstract}
Departmento de Parasitologia, Universidade Federal de Minas Gerais, Belo Horizonte, MG, Brasil *Fundação Ezequiel Dias, Diretoria de Pesquisa e Desenvolvimento, Laboratório de Biologia Molecular e Celular, R. Conde Pereira Carneiro 80, $30510-010$ Belo Horizonte, MG, Brasil **Centro de Pesquisas René Rachou-Fiocruz, Belo Horizonte, MG, Brasil ***Santa Casa de Misericórdia, Belo Horizonte, MG, Brasil
\end{abstract}

Biomphalaria glabrata snails are major hosts for the digenetic trematoda Schistosoma mansoni, the causative agent of human schistosomiasis. The success or failure of the infection will be dependent on the mobilization of the molluskan internal defense system, where a major role will be played by circulating hemocytes produced by the APO (amebocyte-producing organ) of the snail. In this report, the primary culture of the APO region of $\mathrm{B}$. glabrata was obtained for the first time, as well as a control culture of the ovotestis. Three different cell populations migrated easily from the explants in culture, with no need of any dispersion agent. The cells grew in suspension at an incubation temperature of $15^{\circ} \mathrm{C}$ and the cultures were maintained viable for up to two weeks. Two of these cell populations obtained resembled cell types known to be present in the hemolymph of Biomphalaria. The availability of APO cells in culture may contribute to a better understanding of the internal defense in mollusks, in general, as well as the specific response of $\mathrm{B}$. glabrata to $\mathrm{S}$. mansoni infection.

Key words: Biomphalaria - schistosomiasis - Schistosoma mansoni - hemocyte - tissue culture

Schistosomiasis is a parasitic infection caused by the digenetic trematode Schistosoma mansoni Sambom, 1907. The disease is prevalent in 54 countries and territories of Africa, the Caribbean, the Mediterranean, and South America. It is estimated that 130 million people are infected with this species of parasite (Chitsulo et al. 2000). Although several advances have been achieved in the control of the schistosomiasis morbidity, mainly due to the development of new low toxicity and highly effective drugs against the parasite, it is still an endemic disease, whose control and/or eradication is very difficult in the wide regions where it occurs. The affected patients become debilitated, thus impairing the socio-economic development of the affected countries. In Brazil, it is estimated that eight million people are infected, whereas thirty million are at high risk of infection, since they live in hyper endemic areas (Katz 1997).

The human infection starts with the penetration of the skin by larval forms of $S$. mansoni living in infected freshwaters, where the parasite utilizes snails of the genus Biomphalaria Preston 1910 (Mollusca: Pulmonata, Planorbidae) as intermediate hosts. In Brazil, three species of Biomphalaria are considered as hosts for schistosomia-

Financial support: Fundação Ezequiel Dias, Centro de Pesquisas René-Rachou, CNPq (with research fellowships to CL FortesDias and PMZ Coelho)

This work is part of the Doctoral Thesis of L Barbosa with a fellowship from Capes.

${ }^{+}$Corresponding author: consuelo@funed.mg.gov.br

Received 8 March 2006

Accepted 8 June 2006 sis mansoni, in this order of importance: B. glabrata, $B$. tenagophila, and B. straminea.

In the $S$. mansoni-Biomphalaria interaction, besides the stringent physiological and biochemical compatibility between host and parasite, the success or failure of the infection will be strongly determined by the efficacy of the internal defense system of the snail. When in contact with the infective agent, the endogenous defense mechanisms of the mollusk are immediately activated, mediated by circulating effectors cells (hemocytes) and by soluble factors which are present in the hemolymph. Among these factors, lectins with specific carbohydratebinding capacities play an important role by immobilizing foreign objects by agglutination, promoting phagocytes by the hemocytes or even acting as cytophilic receptors for non-self recognition (Van der Knaap \& Loker 1990).

The hemocytes of Biomphalaria are capable of phagocytosis, encapsulation and, finally, destruction of the infective agents. Both morphologically and functionally, these cells resemble cells of the vertebrate monocytemacrophage series (Jeong et al. 1983, Bezerra et al. 2003). Experimental evidence has been accumulated assigning the production and storage of hemocytes to the hematopoietic organ, a structure that is located on the wall of the pericardium and posterior epithelium of the mollusk mantle. That organ, also known as amebocyte-producing organ or APO, is composed of a small quantity of primary ameboblasts that rest on a loose reticulum, which is formed by extensions of smooth muscles and fibroblasts (Jeong et al. 1983). In a recent study, Sullivan et al. (2004) reported an increase in the frequency of cell mitosis in the APO of B. glabrata following the inoculation of miracidia or cercariae antigens of $S$. mansoni. The mitotic ratio was intensified in Biomphalaria strains that were naturally 
resistant to infection by $S$. mansoni. Furthermore, experimental transplantation of several organs from $B$. glabrata specimens from a strain partially resistant to $S$. mansoni infection to individuals from a susceptible strain, demonstrated that the APO was unique in its ability of transfering resistance to the receptors (Sullivan \& Spence 1994). More recently, Barbosa et al. (2006) transformed susceptible strains of $B$. tenagophila into resistant ones by transplantation of the APO from an absolute resistant strain (Taim, RS, Brazil) of the same mollusk species. The transplanted recipients became completely resistant to $S$. mansoni infection.

The present study describes, for the first time, the primary culture of the APO region of $B$. glabrata. The availability of such an in vitro model may provide a useful tool for studying the biology and development of the internal defense system of these snails, as well as a better understanding of the mechanisms of susceptibility or resistance to $S$. mansoni in different Biomphalaria strains. This approach may suggest, perhaps, new alternatives for the control of human schistosomiasis.

\section{MATERIALS AND METHODS}

Materials - Mebendazole (100 mg/pellet) is a pharmaceutical product of the Ezequiel Dias Foundation. The fetal bovine serum (FBS) was processed in our laboratory from a crude stock. CMRL 1415 culture medium was prepared from individual components (Morton 1970) whereas Ham's F-10 (N 6635), Ham's F-12 (N 6760) and RPMI-1640 (R 6504) culture media were prepared according to the manufacturer's instructions (Sigma Co.). Multi-well plates were purchased from Costar Co., and poly-L-lysine ( $\mathrm{P}$ 9155), sodium selenite (S 9133), putrescine (P 5780), progesterone (P 6149), and epidermal growth factor (E 1257) were from Sigma. All the solutions, plastic, glassware and surgical tools used were previously sterilized. All other reagents were of the best grade available.

Mollusks - Two hundred B. glabrata snails, laboratory reared in aquaria at the Research Center René-RachouFiocruz, were used. The specimens were distributed in groups according to the diameter of their typical planorbid shells, a parameter commonly utilized to estimate the animal's age. Individuals with shell diameters between 7 to $40 \mathrm{~mm}$ were tested. The mollusks were kept in beakers with $250 \mathrm{ml}$ of bi-distilled water containing $2.5 \mathrm{mg} / \mathrm{ml}$ mebendazole, a general anti-helminthic drug, for $48 \mathrm{~h}$, until their brownish faeces turned to whitish. The intact shell of the animals was then cleaned with $70 \%$ alcohol and transferred to a laminar-flow cabinet for dissection under aseptic conditions.

Primary cultures - The snail's shells were opened by means of scissors. The soft parts were separated with surgical tweezers and placed in a Petri's dish. The APO region was removed according to the procedure described by Sullivan (1990) and placed in $0.5 \mathrm{ml}$ of PBS for a few seconds in order to prevent desiccation. The APO region was then rapidly sliced into small fragments, which were placed into 12- or 24-well plates containing $500 \mu \mathrm{l}$ or $250 \mu \mathrm{l}$ of culture medium, respectively. After adhesion of the tissue explants, $24 \mathrm{~h}$ later, the volumes of culture medium per well were doubled by addition of fresh medium. The plates were incubated at fixed temperatures of 15 or $20^{\circ} \mathrm{C}$. A control culture was established with the ovotestis of Biomphalaria. The organ was removed and cultured under exactly the same conditions described for the APO region.

The culture media tested were Ham's F-10, Ham's F12, CMRL 1415, and RPMI-1640, containing 10\% fetal bovine serum, $4 \mathrm{mg} / \mathrm{ml}$ fungizon and $10 \mathrm{mg} / \mathrm{ml}$ gentamicin. The collagens of South American rattlesnake (Crotalus durissus terrificus) and rat's tail (Duarte et al. 1999), polyL-lysine and 3\% agar were tested as cell adhesion helpers. Poly-L-lysine was used according to the manufacturer's instructions. Growth promoters and differentiation inducers for vertebrate cells, such as insulin $(1.25 \mu \mathrm{g} /$ $\mathrm{ml})$, sodium selenite $(30 \mathrm{ng} / \mathrm{ml})$, putrescine $(0.3 \mu \mathrm{g} / \mathrm{ml})$, transferrin $(5 \mu \mathrm{g} / \mathrm{ml})$, and EGF $(0.1 \mathrm{ng} / \mathrm{ml})$, were also tested.

Viability of the primary cell cultures was determined using the trypan blue dye exclusion method and further counting of viable and non-viable cells using a hemocytometer.

Cells from the hemolymph of Biomphalaria - The hemolymph of B. glabrata snails (about $200 \mu \mathrm{l} /$ specimen) was removed from the hepato-pancreas region by means of a syringe with an insulin needle and pooled together. After enzymatic digestion with the same volume of $0.025 \%$ trypsin-0.02 MEDTA for $10 \mathrm{~min}$, at room temperature, to help in cell dispersion, the solution was centrifuged at $3000 \mathrm{rpm}$ for $2 \mathrm{~min}$. The cell pellet was suspended in 200 $\mu 1$ PBS and immediately stained with methylene blue.

Cells staining by methylene blue - Slides were prepared with cells from the primary culture or from the hemolymph pool. In either case, the cells were fixed in $4 \%$ paraformaldeyde for $1 \mathrm{~h}$, washed once with PBS and centrifuged at $2000 \mathrm{rpm}$. The pellet was suspended in $1 \%$ methylene blue in distilled water and gently dropped in slides. After mild flame heating, the slides were covered and examined under the microscope. All the previous steps were performed at room temperature.

\section{RESULTS}

Cell culture conditions - The cell culture experiments were carried out with mollusks whose shell diameters varied between 12 and $18 \mathrm{~mm}$. Among the culture media tested, the best results were obtained with CMRL 1415 supplemented with insulin, transferrin, sodium selenite, putrescine, EGF, and FBS. Under this condition, the cells viability was $75 \%$ in average, after one week in culture. From the second week onwards, signs of cell death were progressively observed, such as the presence of granulations in the cytoplasm and swelling followed by lysis. The cultures, then, were maintained for a maximum period of two weeks. In the absence of FBS there was nor cell migration from the explants of the APO region neither cell growth, whereas in the cultures without EGF the growing cells consisted mainly of fibroblasts. No significant differences were observed in the growth pattern in the presence of adhesion substrates. The best temperature for cell growth was $15^{\circ} \mathrm{C}$, which also favored the migration of cells from the APO explants. The migration was impaired 
when the incubation temperature was raised to $20^{\circ} \mathrm{C}$, followed by death of every cell present within the first $24 \mathrm{~h}$. After 1 week at $15^{\circ} \mathrm{C}$, the temperature increase to $20^{\circ} \mathrm{C}$ led to a rapid decrease in cell viability from 75 to $5 \%$ within $24 \mathrm{~h}$.

Cell types in culture - The cells migrated effortlessly from the explants of the APO region, with no need of any enzymatic treatment to assist cell dispersion in culture. A number of cells already dispersed in the medium could be observed starting from the very first day of culture (Fig. 1).
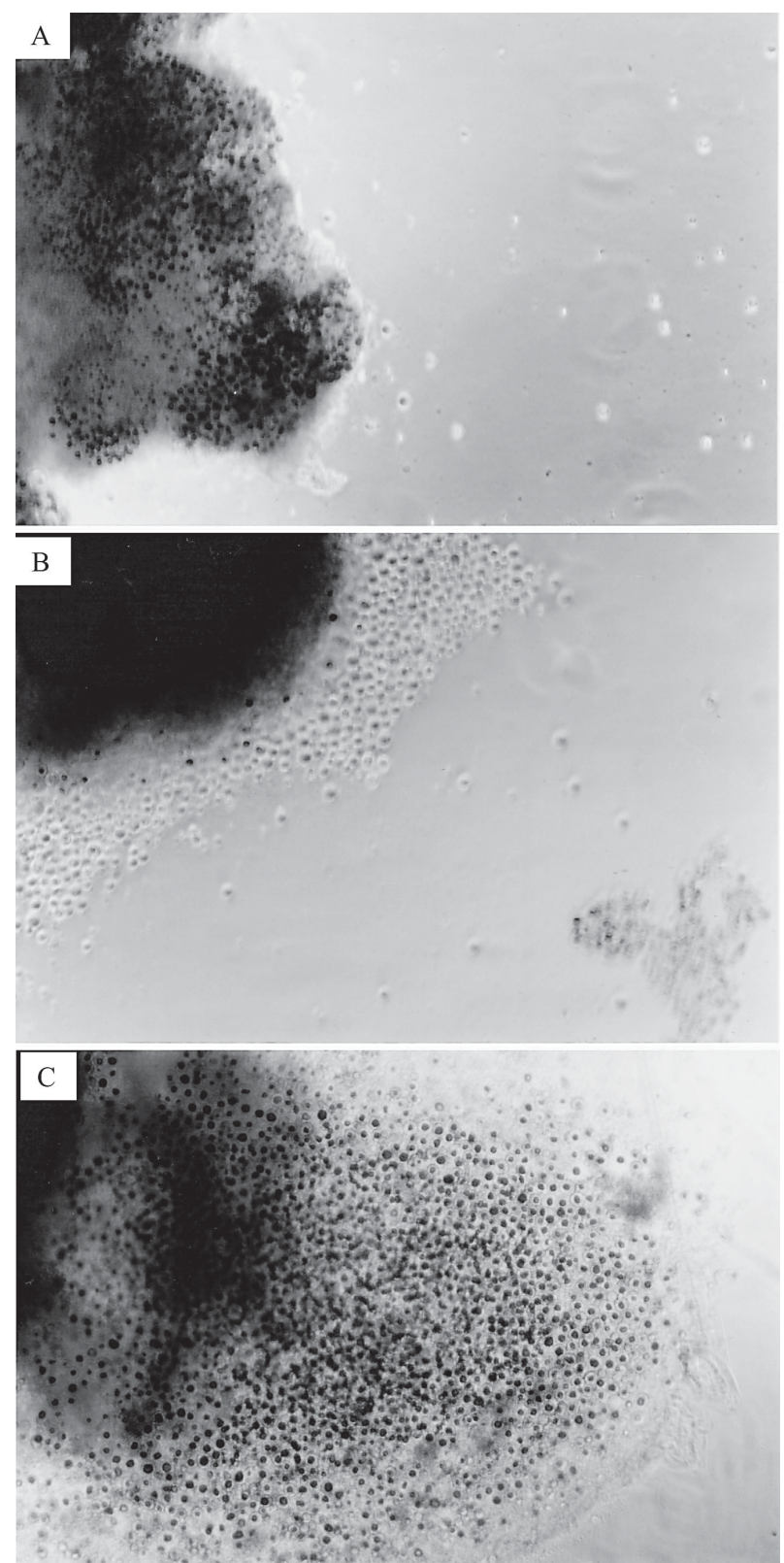

Fig. 1: migration pattern of cells from the explants of the region of the amebocyte-producing organ of Biomphalaria glabrata in culture. Time in culture - A: immediately after the explantation of the amebocyte-producing organ; B: $24 \mathrm{~h}$ later; C: $36 \mathrm{~h}$ later. Magnification: $100 \times$.
Three cell populations or types morphologically distinct, named I to III, grew in suspension in the cultures of the APO region (Fig. 2). These closely resembled two cell types known to occur in the hemolymph of Biomphalaria. Type I cells (Fig. 2A,B), which comprised the predominant population in culture, were rounded with a high nucleus to cytoplasm ratio, morphologically similar to hyalinocytes of the hemolymph (Van der Knaap \& Loker 1990). The cell population type II displayed relatively more cytoplasm than type I (Fig. 2A,B) in accordance with the description of granulocytes from the hemolymph (Van der Knaap \& Loker 1990). Extended pseudopods, previously reported as an important ability of granulocytes, were also observed in the cultures (Fig. 2C). However, it was not possible to identify the cell type they came from. The last cell population in culture, named III, was characteristically light-refringent under phase-contrast microscopy, with no defined nuclei (Fig. 2B). This population was much less abundant than the previous two and, as far as we know, has not been reported before in the molluskan hemolymph. Interestingly, atypical cell division, with nuclei duplication without concomitant cytokinesis, was observed in the cultures after the cells migrated from the explants of the APO region (Fig. 2D).

In the primary culture of the ovotestis (control) the cells grew in clusters, strongly adhered to the substrate (Fig. 3).

A single cell type was observed in the hemolymph of B. glabrata, the morphological and staining pattern of which resembled the cells from population II in the primary cultures of the molluskan APO region (Fig. 4A, B, respectively).

\section{DISCUSSION}

The first trials of tissue culturing of the APO region were performed with $B$. glabrata specimens with shell

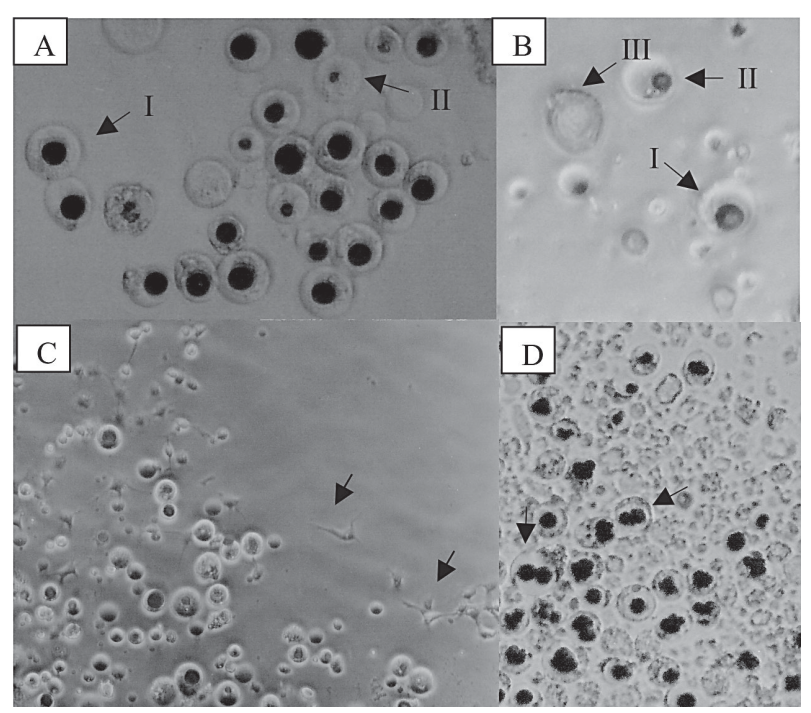

Fig. 2: cells in the primary cultures of the region amebocyte-producing organ of Biomphalaria. A: cell types I and II with predominance of the first; B: cell types I, II, and III; C: pseudopods released by cells; D: binucleated cells. Magnification: $200 \times$. 


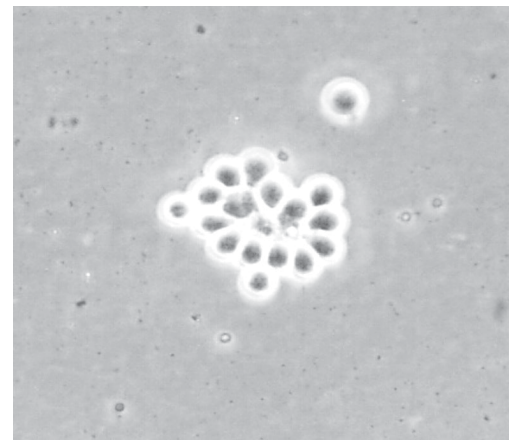

Fig. 3: cells in the primary culture of the ovotestis of Biomphalaria used as control. Magnification: 200×.

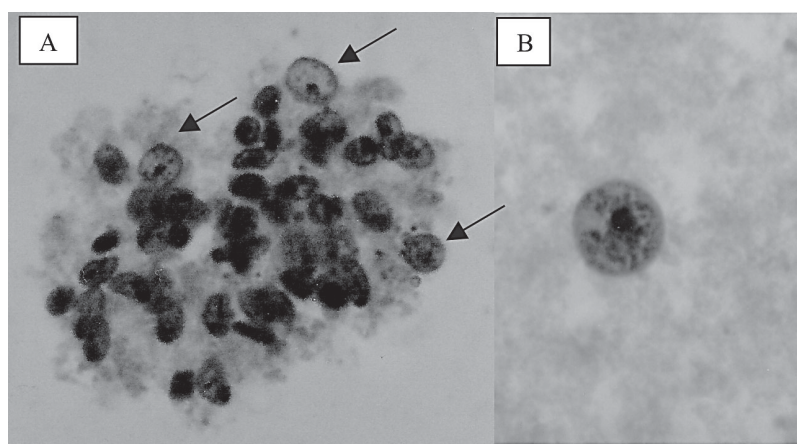

Fig. 4: comparison of cell type II (indicated by the arrow) in the primary culture of the region of the amebocyte-producing organ (A) and similar circulating cell in the hemolymph of Biomphalaria glabrata (B) after fixation and staining by methylene blue. Magnification: A: $400 \times$; B: $1000 \times$.

diameters between 6 and $40 \mathrm{~mm}$. Handling and dissection of younger specimens (shell diameters below $12 \mathrm{~mm}$ ) were hampered by their small size. The first difficulty encountered with much older specimens (shell diameters above $20 \mathrm{~mm}$ ) was the high rate of natural contamination of the mollusks by a variety of endoparasites. About $50 \%$ of the specimens had to be discarded in the very first days in the laboratory due to the persistence of high levels of parasitism even after mebendazol treatment. Individuals with shell diameters between 12 and $18 \mathrm{~mm}$ were the most responsive to the drug and with a reduction of up to $90 \%$ in the contamination rate. These specimens were, then, used in the experiments.

The number of circulating hemocytes was previously described to be highly variable in Biomphalaria and mainly dependent on parameters such as the method and local of hemolymph extraction besides the physiological conditions of the snail (Sminia 1981). Similarly, there is no agreement in the literature on the number and relative frequency of the cell types most commonly found in the hemolymph of Biomphalaria. The hemocytes do not behave as a homogeneous population and morphological/ biochemical heterogeneity among them have been described by several authors. Sminia et al. (1983) reported that gastropods, in general, possess a unique type of hemocyte, which suffers morphological changes during cell maturation. The youngest cells are rounded and highly active for mitoses, whereas the mature ones display cytoplasmatic indentations, low mitotic and high phagocytic activities. The presence of two sub-populations of hemocytes mainly differing in size, phagocytic activity and ability to emit pseudopods, was demonstrated by others (Cheng \& Auld 1977, Van der Knaap \& Loker 1990, Barraco et al. 1993, Johnston \& Yoshino 2001). On the other hand, three hemocyte cell types were described by Matricon-Gondran and Letocart (1999). Among these, one cell type was found to share typical properties of mammalian macrophages, such as high phagocytosis activity, resistance to elevated doses of gamma radiation and the presence of inner lysosomal structures (Bezerra et al. 2003). An even higher number of hemocyte types were described by Joky et al. (1983). Up to four cell types were proposed based not only on morphological characteristics, but also on their ability of expressing different surface lectin receptors. Independently of the inconsistency in the definition and characterization of types, there is a consensus that the hemocytes and their products represent the basic elements of the innate defense system of Biomphalaria, responsible for the phagocytosis or encapsulation of small size (bacteria, fungi and protozoa) or large size (larvae of helminthes) pathogens, respectively (Adema \& Loker 1997).

A significant number of authors have reported the presence of two sub-populations of hemocytes, the so called granulocytes and hyalinocytes (Cheng \& Auld 1977, Van der Knaap \& Loker 1990, Barraco et al. 1993). With 5 to $8 \mu \mathrm{m}$ in diameter and a large nucleus to cytoplasm ratio, the hyalinocytes have a circular contour when in contact with polished glass surfaces, little tendency to form pseudopods and scarce lysosomal structure. On the other hand, the granulocytes have diameters between 7 and $11 \mu \mathrm{m}$ with more cytoplasm. They emit pseudopods, are active in phagocytosis and represent more than $90 \%$ of the circulating cells (Barraco et al. 1993). This observation explains why a single cell population, was observed in the hemolymph of B. glabrata, most probably corresponding to this major population (granulocytes).

Two cell types, similar to the two hemocyte populations previously described based mainly on their nucleus to cytoplasm ratio, were observed in the cultures of the APO region of B. glabrata. These cultures, unfortunately, were limited to short-term ones. Indeed, the difficulty of obtaining hemocytes growing in vitro was pointed out before (Lynn 2001). One possible reason for that could be the low proliferation rate of the cells (Lebel et al. 1996). The morphology of the cells that grew in the primary culture of the ovotestis (control) was totally distinct of the cell populations observed in the culture of the APO region. These data suggest that the origin of hemocytes is possibly restricted to specific organs/regions, such as the APO of Biomphalaria. Recently, based on morphological data, Souza and Andrade (2006) suggested a multicentric origin of the hemocytes, starting at the endothelium of vascular spaces.

Due to the limited data available for the culturing of hematopoietic tissues of invertebrates, our attempts were based on studies in vertebrates, in which the proliferation/differentiation rates are known to be controlled by 
hormones, growth factors, cytokines, surface receptors, and genes (Watt \& Hogan 2000). Cultures of invertebrate tissues have been described as being insensitive to many of these factors that affect vertebrate systems (Slack 2000, Watt \& Hogan 2000). However, Lebel et al. (1996) reported a positive effect in invertebrate cell cultured in the presence of fetal bovine serum and epidermal growth factor. Our data are in accordance to the aforementioned results.

The present work describes for the first time the successful primary culture of the APO region of B. glabrata. Further work is in progress to isolate the cell populations obtained so far in the primary cultures with the aim of gaining a more detailed morphological and functional characterization.

\section{ACKNOWLEDGEMENTS}

To Ms MS Hermógenes and AC Valentim for excellent technical assistance. To Ms DMS Reis, DM Repetição, and SSF Teixeira, technicians in charge of the maintenance of the Biomphalaria aquaria at the CPqRR-Fiocruz.

\section{REFERENCES}

Adema CM, Loker ES 1997. Specificity and immunobiology of larval digenean-snail associations. In B Fried, TK Graczyk (eds), Advances in Trematode Biology, CRC Press, Boca Raton, p. 229-264.

Barbosa L, Caldeira RL, Carvalho OS, Vidigal THDA, JannottiPassos LK, Coelho PMZ 2006. Resistance to Schistosoma mansoni by transplantation of APO Biomphalaria tenagophila. Parasite Immunol 28: 209-212.

Barraco MA, Steil AA, Gargioni R 1993. Morphological characterization of the hemocytes of the pulmonate snail Biomphalaria tenagophila. Mem Inst Oswaldo Cruz 88: 7383.

Bezerra FSM, Nogueira-Machado JA, Martins-Souza RL, Chaves MM, Correa RF, Coelho PMZ 2003. Effect of gamma radiation on the activity of hemocytes and on the course of Schistosoma mansoni infection in resistant Biomphalaria tenagophila snail. Mem Inst Oswaldo Cruz 98: 73-75.

Cheng TC, Auld KR 1977. Hemocytes of the pulmonate gastropod Biomphalaria glabrata. J Invertebr Pathol 30: 119-122.

Chitsulo L Engels D, Montresor A, Saviolli L 2000. The global status of schistosomiasis and its control. Acta Trop 77: 41-51.

Duarte MM, Montes de Oca H, Diniz CR, Fortes-Dias CL 1999. Primary culture of venom gland cells from the South American rattlesnake (Crotalus durissus terrificus). Toxicon 37: 1673-1682.

Jeong KH, Lie KJ, Heyneman D 1983. The ultra structure of the amebocyte-producing organ in Biomphalaria glabrata. Dev Comp Immunol 7: 217-228.

Johnston L, Yoshino TP 2001. Larval Schistosoma mansoni excretory-secretory glycoproteins (ESPs) bind to hemocytes of Biomphalaria glabrata (Gastropoda) via surface carbohydrate binding receptors. J Parasitol 87: 786-793.

Joky A, Matricon-Gondran M, Benex J 1983. Fine structural differences in the amoebocytes of Biomphalaria glabrata. Dev Comp Immunol 7: 669-672.

Katz N 1997. Vacina polivalente anti-helminto. Biotecnol Ci Desenvolv (Brasília) 2: 34-35.

Lebel JM, Giard W, Favrel P, Boucaud-Camou E 1996. Effects of different vertebrate growth factors on primary cultures of hemocytes from the gastropod mollusk, Haliotis tuberculata. Biol Cell 86: 67-72.

Lynn DE 2001. Novel techniques to establish new insect cell lines. In Vitro cell Dev Biol 37: 319-321.

Matricon-Gondran M, Letocart M 1999. Internal defenses of snail Biomphalaria glabrata. I. Characterization of hemocytes and fixed phagocytes. J Invertebr Pathol 74: 224-234.

Morton HJ 1970. A survey of commercially available tissue culture media. In vitro 6: 89-108.

Slack JM 2000. Stem cells in epithelial tissues. Science 287: 1431-1433.

Sminia T 1981. Gastropods. In NA Ratcliffe, AF Rowley (eds), Invertebrate Blood Cells, Academic Press, London.

Sminia T, Van Der Knaap WP, Van Asselt LA 1983. Blood cell types and blood cell formation in gastropod mollusks. Dev Comp Immunol 7: 665-668.

Souza SS, Andrade ZA 2005. A origem da célula de defesa (hemócitos) na Biomphalaria glabrata quando infectada pelo Schistosoma mansoni. Proceedings of the 10th International Symposium on Schistosomiasis. September 25-28, Belo Horizonte, MG, p. 177.

Sullivan JT 1990. Long-term survival of heterotopic allografts of the amebocyte- producing organ in Biomphalaria glabrata (Mollusca: Pulmonata). Trans Am Microsc Soc 109: 52-60.

Sullivan JT, Spence JV 1994. Transfer of resistance to Schistosoma mansoni in Biomphalaria glabrata by allografts of amebocyte-producing organ. J Parasitol 80: 449-453.

Sullivan JT, Pikios SS, Alonzo AQ 2004. Mitotic responses to extracts of miracidia and cercariae of Schistosoma mansoni in the amebocyte-producing organ of the snail intermediate host Biomphalaria glabrata. J Parasitol 90: 92-96.

Van Der Knaap WP, Loker ES 1990. Immune mechanisms in trematode-snail interactions. Parasitol Today 6: 175-182.

Watt FM, Hogan BL 2000. Out of Eden: stem cells and their niches. Science 287: 1427-1430. 
